\title{
Tuvinian Language
}

National Cancer Institute

\section{Source}

National Cancer Institute. Tuvinian Language. NCI Thesaurus. Code C154183.

A T urkic language spoken in the Republic of Tuva in south-central Siberia in Russia. 